\title{
Variable Penetrance among Different Sources of the Male Fertility Restoration Allele of Onion
}

\author{
Hsiang-I Lee \\ Fengshan Tropical Horticultural Experiment Branch, Taiwan Agricultural \\ Research Institute, Kaohsiung 83052, Taiwan, Republic of China; and \\ Department of Horticulture, University of Wisconsin, Madison, WI 53706 \\ Michael J. Havey \\ USDA ARS and Department of Horticulture, University of Wisconsin, \\ Madison, WI 53706
}

Additional index words. CMS, cytoplasmic male sterility, male fertility, pollen stainability

\begin{abstract}
Hybrid onion (Allium cepa) seed is produced using cytoplasmic male sterility (CMS). For the most commonly used source of onion CMS, male fertile plants possess male sterile (S) cytoplasm and dominant allele(s) at one nuclear male fertility locus $(M s)$. Because male fertility restoration is not necessary for bulb production, it is desirable to purge dominant alleles at $M s$ from populations and breeding lines to facilitate the development of male sterile inbreds for hybrid production. In this research, we used molecular markers to establish the cytoplasms and genotypes at $M s$ in progenies from testcrosses of male sterile lines with plants from three populations [B2354, Ailsa Craig (AC), and Sapporo-Ki (Ski)] possessing the dominant Ms allele. We scored male fertility of testcross progenies by visual examination of flowers and acetocarmine staining of pollen. Different sources of the dominant $M s$ allele showed significantly different amounts of male fertility restoration and proportions of stainable pollen, complicating visual selection against the dominant $M s$ allele. For $\mathrm{AC}$ and Ski, molecular markers correctly predicted male sterility vs. male fertility of progenies in the greenhouse and field. However, for B2354, male fertility restoration was less clear and especially difficult to score under field conditions, consistent with reduced penetrance of male fertility restoration for this source of the dominant $M s$ allele. These results will be of interest to onion breeders selecting S-cytoplasmic male sterile lines for hybrid onion development.
\end{abstract}

Hybrid onions are widely grown throughout the world and are commonly produced using CMS lines as seed parents (Havey, 2000). For the most commonly used source of CMS in onion, male sterility results from the interaction of male sterile (S) cytoplasm with the homozygous recessive genotype at one nuclear male fertility restoration locus (Ms) (Jones and Clarke, 1943). Breeders work to eliminate the dominant allele at $M s$ from populations to ensure stable expres-

\footnotetext{
Received for publication 12 Nov. 2019. Accepted for publication $3 \mathrm{Feb} .2020$.

Published online 28 February 2020

We gratefully acknowledge the technical help of Christy Stewart.

Names are necessary to report factually on available data; however, the U.S. Department of Agriculture (USDA) neither guarantees nor warrants the standard of the product, and the use of the name by USDA implies no approval of the product to the exclusion of others that may also be suitable. USDA is an equal opportunity provider and employer.

M.J.H. is the corresponding author. E-mail: michael. havey@usda.gov.

This is an open access article distributed under the CC BY-NC-ND license (https://creativecommons. org/licenses/by-nc-nd/4.0/).
}

sion of male sterility and because male fertility restoration is not necessary for bulb production. Historically, it has been timeconsuming to select against dominant alleles at $M s$ from onion populations because male fertile plants must be testcrossed as males to male sterile plants and testcross progenies evaluated for male fertility. This process may not be conclusive because the dominant allele at $M s$ may show reduced penetrance (Melgar and Havey, 2010). The elimination of dominant $M s$ alleles has become easier with the use of robust molecular markers in linkage disequilibrium with $M s$ (Havey and von Kohn, 2017; Kim et al., 2015), allowing breeders to genotype and select plants before flowering and crossing. Over the years, we have noticed that some sources of the dominant $M s$ allele appear to clearly restore male fertility in testcrosses with S-cytoplasmic plants, whereas other sources were difficult to visually score as male sterile vs. fertile. In this research, we scored male fertility restoration and pollen stainability in onion families possessing S cytoplasm and segregating for the dominant allele at $M s$ from three different sources. We observed that male fertility restoration conditioned by one source of the dominant $M s$ allele was incomplete and particularly difficult to score.
Plant materials. Three sources of the dominant $M s$ allele were used for this research:

1. Sapporo-Ki (Ski) is an open-pollinated (OP) onion population grown in northern Japan and likely originated from long-day storage onion from North America (Goldman et al., 2000). The cytoplasm of random plants from Ski were determined using chloroplast markers revealed by DNA gel blots and polymerase chain reaction (PCR) (Havey, 1993; 1995), and plants possessing normal $(\mathrm{N})$ male fertile cytoplasm were self-pollinated and testcrossed to Scytoplasmic male sterile plants. Seed from testcrosses was planted in field plots, bulbs were harvested and vernalized at 4 to $7{ }^{\circ} \mathrm{C}$ for at least 6 months, and plants flowered and were scored for male fertility restoration. Families from self-pollination of the Ncytoplasmic Ski plants were chosen if the testcross families segregated for male fertility restoration, indicating that the male parent was heterozygous at Ms. Progenies from these selected families were repeatedly self-pollinated and testcrossed to S-cytoplasmic male sterile plants to produce the $\mathrm{S}_{5}$ generation, selecting in each generation for heterozygosity at $M s$ (Fig. 1). $\mathrm{S}_{5}$ progenies heterozygous at $M s$ were caged together and intercrossed using flies, and in the same cage testcrossed to male sterile plants of inbred Ski-1A, which was also selected from Ski (Havey and Bohanec, 2007). In this cage, flowers of Ski-1A were closely observed for viable pollen and no male fertile plants were identified.

2. Ailsa Craig $(\mathrm{AC})$ is an $\mathrm{OP}$ onion grown in the United Kingdom, and AC43 resulted from self-pollination of a single plant from this OP (King et al., 1998). AC43 was crossed as the male with BYG15-23 (N-cytoplasmic and homozygous recessive at $M s$ ) and a segregating $\mathrm{F}_{2}$ family was developed (King et al., 1998). $\mathrm{F}_{2}$ progenies were self-pollinated and testcrossed to Scytoplasmic male sterile plants, and one $\mathrm{F}_{3}$ family (USDA breeding plot 16278) homozygous dominant at $M s$ was selected and used by Melgar and Havey (2010) to demonstrate reduced penetrance of the dominant $M s$ allele. Plants from family 16278 were crossed as males to a male sterile inbred line, and male fertile progenies were Scytoplasmic and heterozygous at $\mathrm{Ms}$. These male fertile progenies were selfpollinated and at the same time testcrossed to a male sterile plant. Testcross progenies were evaluated for male fertility to identify male parents heterozygous at Ms. This process was repeated 
for three generations, producing an inbred (AC) that possesses S cytoplasm and is heterozygous at $M s$ (Fig. 1). AC was caged with male sterile plants of MSU611AxMSU611-1B (SB80A), the female parent of the hybrid 'Spartan Banner 80' (Goldman et al., 2000), and crossed using flies. Flowers of SB80A were closely observed for viable pollen and no male fertile plants were identified.

3. Inbred $\mathrm{B} 2354 \mathrm{~A} \& \mathrm{~B}$ is a male sterile $(\mathrm{A}=\mathrm{S} m s m s)$ and maintainer $(\mathrm{B}=\mathrm{N}$ msms) pair selected after intercrossing among diverse onion inbreds and was released by the USDA in 1997 (Goldman et al., 2000). B2354A is expected to be male sterile; however, this line has produced $\approx 5 \%$ male fertile plants over numerous seed production cycles. The cytoplasm of random plants from B2354B was determined using the chloroplast markers described previously, and all plants possessed normal $(\mathrm{N})$ male fertile cytoplasm. These plants were selfpollinated and testcrossed to B2354A. Flowers of B2354A were closely observed for viable pollen, and any male fertile plants were discarded. Testcross seed was planted in field plots, bulbs were harvested and vernalized, and plants flowered and were scored for male fertility restoration as described. Progenies from self-pollination of B2354B plants were chosen if the testcross families were uniformly male sterile, indicating that the male parent should have been homozygous recessive at Ms. These progenies were intercrossed in a cage with B2354A (Fig. 1). Flowers of B2354A in this cage were observed for viable pollen and male fertile plants were discarded.

Progenies from Ski 1A $\times$ Ski, SB80A $\times$ $\mathrm{AC}$, and $\mathrm{B} 2354 \mathrm{~A} \times \mathrm{B} 2354 \mathrm{~B}$ were grown in 2018 in a commercial field at Palmyra, WI, and bulbs were harvested and vernalized as described. Random samples of at least 15 progenies from each testcross family were grown and scored for male fertility restoration and pollen staining. In Mar. 2019, bulbs were planted in pots containing a soilless mix (Metro Mix; Sun-Gro Horticulture, Agawam, MA) and randomly placed in a greenhouse with $25{ }^{\circ} \mathrm{C}$ days and $20{ }^{\circ} \mathrm{C}$ nights with supplemental lighting for $14 \mathrm{~h}$. Flowers were examined for male fertility vs. sterility and anthers were sampled for pollen staining in May 2019. A second planting occurred in May 2019 in a greenhouse with the same environmental conditions, and flowers were examined and anthers were sampled for pollen staining in late June. A third planting occurred in May 2019 in a field at the University of Wisconsin Arlington Research Farm and flowers were examined and anthers were sampled for pollen staining in July 2019.
Phenotypic scoring and pollen staining. Testcross progenies were scored as male fertile vs. sterile by visual examinations of flowers looking for plumb anthers and presence of pollen. Onion flowers are protandrous and pollen matures before the style elongates and the stigmatic surface becomes receptive (Currah and Ockendon, 1978). In each flower, there are two whorls of three anthers each; the inner whorl dehisces first, followed by anthers in the outer whorl. We visually examined flowers in which the inner whorl appeared to be dehiscing or if mature, we scored the outer whorl of anthers before the style had fully elongated. Flowers in umbels were visually scored three times before flowers had elongated styles and dry anthers. Anthers were harvested when $40 \%$ to $50 \%$ of the flowers of the umbels had dehisced. At two different times for each plant predicted to be male fertile based on the molecular markers, two samples of 10 anthers were randomly collected from flowers with dehiscing anthers across the umbel and pollen was stained with $1 \%$ acetocarmine. One hundred pollen grains from each sample were scored as stained (strongly staining nuclei with cytoplasm) vs. nonstaining (little to no stain visible) using a light microscope (Heslop Harrison, 1992). Pollen germination was estimated by incubation on the medium reported by Gomes et al. (2000) modified with $200 \mathrm{~g} \cdot \mathrm{L}^{-1}$ sucrose and $50 \mathrm{mg} \cdot \mathrm{L}^{-1}$ boric acid for $7 \mathrm{~d}$ at $24{ }^{\circ} \mathrm{C}$, during which 100 pollen were scored as germinated with pollen tubes vs. no tubes.

DNA isolations and marker genotyping. Total genomic DNA was extracted from leaves of testcross progenies using a minipreparation (NucleoSpin Plant II Genomic DNA Kit; Macherey-Nagel, Düren, Germany), quantified (NanoDrop; Thermo-Fisher, Waltham, MA), diluted to $10 \mathrm{ng} \cdot \mu \mathrm{L}^{-1}$ with $\mathrm{TE}$ buffer, and stored at $-20{ }^{\circ} \mathrm{C}$ until use. For cytoplasmic determinations, the $a c c D$ indel (von Kohn et al., 2013) was used to confirm that all testcross progenies possessed S cytoplasm. Nuclear genotypes at the $M s$ locus were determined using the AcPms1 marker (Havey and von Kohn, 2017; Kim et al., 2015). Highresolution melting (HRM) real-time PCR (LightCycler 480 II; Roche, Basel, Switzerland) was used for amplification and amplicon detection for both markers. For HRM detection of the $a c c D$ indel, primers were 5'-AGAATGAGGAGCAGGAAA and 5' AGTCGTGATTGTTACTCTT with $50 \mathrm{ng}$ of DNA, $0.25 \mu \mathrm{M}$ of each primer, and $5 \times$ HRM mix (HOT FIREPol EvaGreen; Solis BioDyne, Tartu, Estonia). Amplification consisted of an initial preincubation step at $95{ }^{\circ} \mathrm{C}$ for $15 \mathrm{~min}$, followed by an amplification step of 45 cycles of $95{ }^{\circ} \mathrm{C}$ for $15 \mathrm{~s}, 62^{\circ} \mathrm{C}$ for $30 \mathrm{~s}$, and $72{ }^{\circ} \mathrm{C}$ for $15 \mathrm{~s}$, a melting curve step at $95{ }^{\circ} \mathrm{C}$ for $1 \mathrm{~min}$ and $40{ }^{\circ} \mathrm{C}$ for $2 \mathrm{~min}$, heating again to $68^{\circ} \mathrm{C}$ for $1 \mathrm{~s}$, melting at $0.02{ }^{\circ} \mathrm{C} \cdot \mathrm{s}^{-1}$ with continuous acquisition of fluorescence until $88^{\circ} \mathrm{C}$, and cooling at $40{ }^{\circ} \mathrm{C}$ for $30 \mathrm{~s}$. Genotypes at

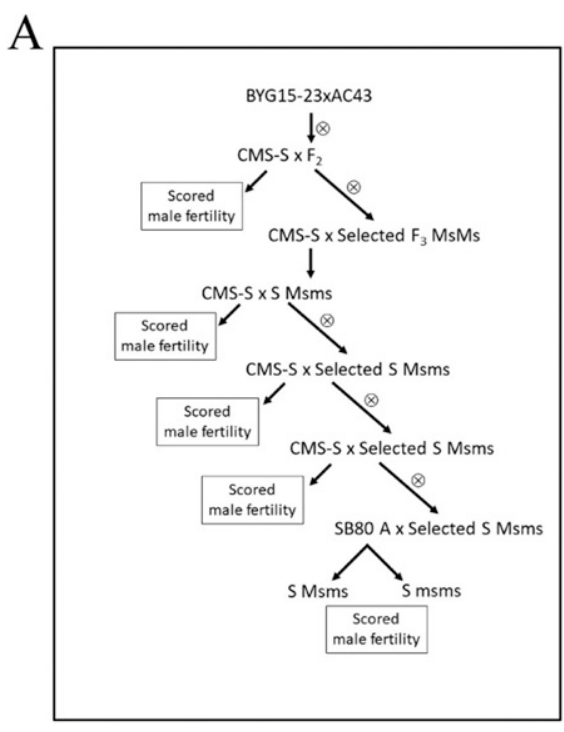

B

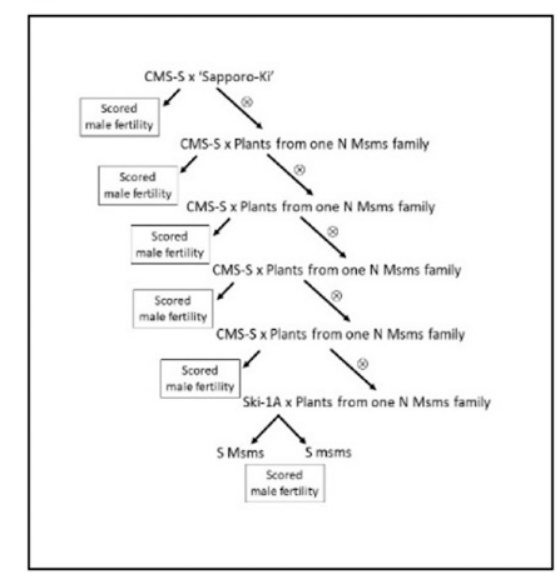

C

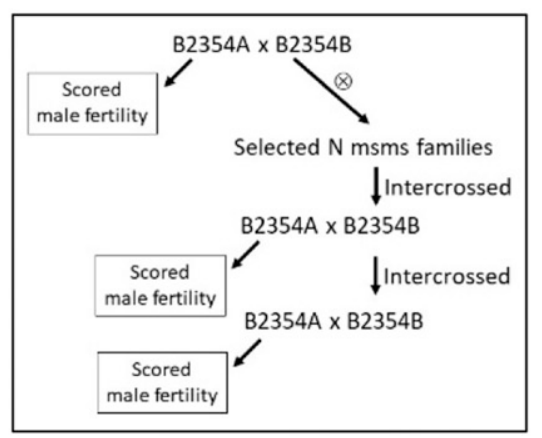

Fig. 1. Pedigrees of testcross progenies from selections of 'Ailsa Craig' (A), 'Sapporo-Ki' (B), and B2354B (C) scored for male fertility restoration across environments. CMS-S is a cytoplasmic male sterile line or plant; $\mathrm{N}$ indicates normal male fertile cytoplasm. $M s$ and $m s$ are the dominant and recessive alleles, respectively, at the nuclear $M s$ locus.

AcPms 1 were determined using primers $5^{\prime}$ ATATCGAAATTCAAATTCCAAACA and 5'-GTTTCCTCGTTGACTTT CTTTACC (Kim et al., 2015), which are the same reagent concentrations as those used for accD, a preincubation step at $95{ }^{\circ} \mathrm{C}$ for $15 \mathrm{~min}$, followed by an amplification step of 44 cycles of $98^{\circ} \mathrm{C}$ for $5 \mathrm{~s}, 65^{\circ} \mathrm{C}$ for $30 \mathrm{~s}$, and $72^{\circ} \mathrm{C}$ for 


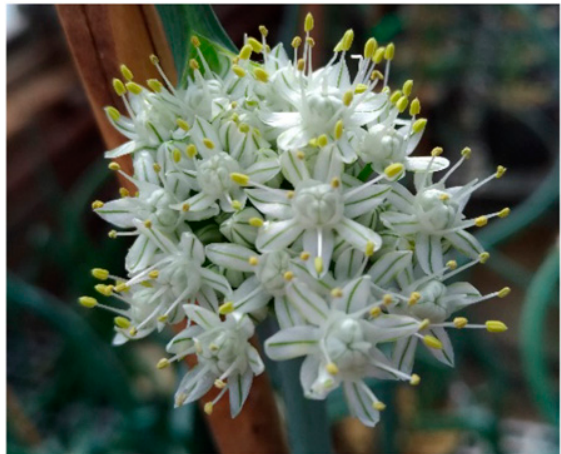

Fig. 2. Umbel of male fertility restored onion from Ski$1 \mathrm{~A} \times$ Ski with plumb anthers and visible pollen.

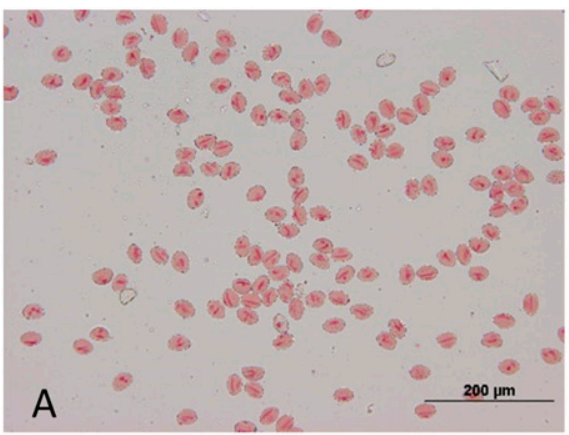

$50 \mathrm{~s}$, a melting curve step at $95^{\circ} \mathrm{C}$ for $1 \mathrm{~min}$, $40{ }^{\circ} \mathrm{C}$ for $2 \mathrm{~min}$, and $69^{\circ} \mathrm{C}$ for $1 \mathrm{~s}$, and cooling at $40{ }^{\circ} \mathrm{C}$ for $30 \mathrm{~s}$. HRM curves were obtained by melting at a rate of $0.02{ }^{\circ} \mathrm{C} \cdot \mathrm{s}^{-1}$ from 69 to $84{ }^{\circ} \mathrm{C}$.

Statistical analyses. Samples of the percentage of stainable pollen were averaged and then arcsine square root-transformed before statistical analysis; normality and homogeneity of variances were confirmed by the Shapiro Wilk and Levene tests using SAS Enterprise Guide 7.1 software (SAS Institute, Cary, NC). Two-way analysis of variance (ANOVA), Tukey's honestly significant difference test $(P=0.05)$, and Kendall's coefficient of concordance for

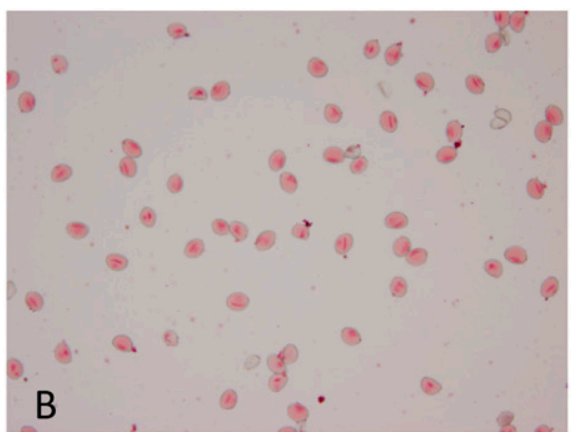

pollen stainability and germination were calculated using SAS.

\section{Results and Discussion}

Visual scoring of male fertility vs. sterility fit the expected 1:1 ratio for testcross families from AC (14:18; $P=0.48)$ and Ski $(24: 25$; $P=0.89$ ), and anthers on male fertile progenies had clearly visible pollen (Fig. 2). The nuclear AcPms1 marker cosegregated with male-fertility restoration in AC and Ski, consistent with the robustness of this marker in other populations (Havey and von Kohn, 2017; Kim et al., 2015). Across the three environments, 50 plants of B2354A flowered

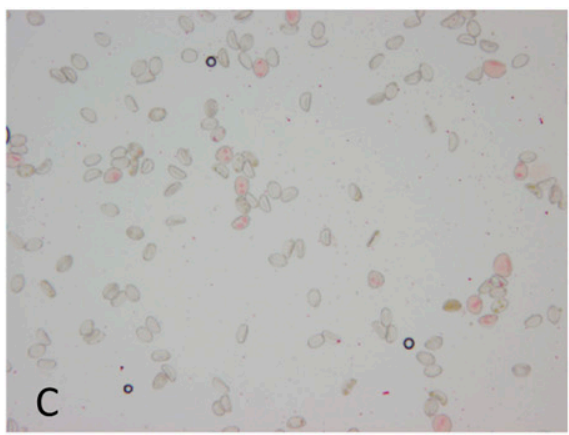

Fig. 3. Acetocarmine-stained pollen from male fertility-restored testcross progenies from (A) Ski, (B) AC, and (C) B2354.

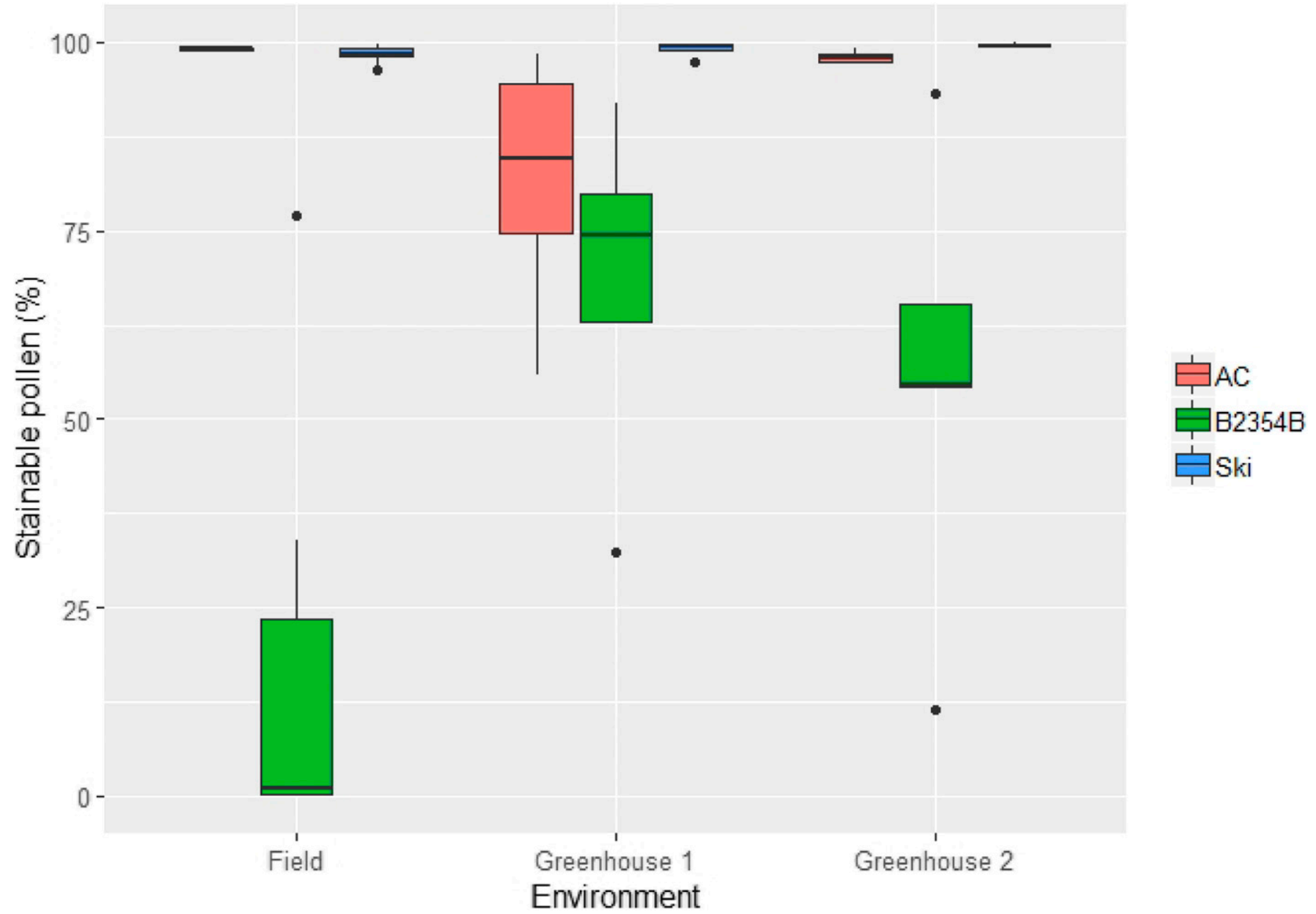

Fig. 4. Boxplots of the percentage of acetocarmine-stained pollen from umbels of male fertility-restored testcross progenies from Ski, $\mathrm{AC}$, and $\mathrm{B} 2354$ grown in three environments. 
Table 1. Mean percentage (\%) of stainable pollen from male fertility-restored testcross progenies from onion lines B2354, AC, and Ski across greenhouse and field environments.

\begin{tabular}{lccc}
\hline & \multicolumn{3}{c}{ Stainable pollen (\%) } \\
\cline { 2 - 4 } Parent & Greenhouse 1 & Greenhouse 2 & Field \\
\hline B2354 & $68.3 \mathrm{~b} \mathrm{(a})^{\mathrm{z}}$ & $55.7 \mathrm{~b}(\mathrm{a})$ & $13.1 \mathrm{~b} \mathrm{(b)}$ \\
AC & $82.1 \mathrm{~b} \mathrm{(a)}$ & $98.0 \mathrm{a} \mathrm{(a)}$ & $99.1 \mathrm{a} \mathrm{(a)}$ \\
Ski & $99.1 \mathrm{a} \mathrm{(ab)}$ & $99.6 \mathrm{a} \mathrm{(a)}$ & $98.4 \mathrm{a} \mathrm{(b)}$ \\
\hline
\end{tabular}

${ }^{\mathrm{z}}$ Means followed by the same letter in parentheses in columns and rows were not significantly different using Tukey's honestly significant difference test at $P=0.05$.

and were scored for male fertility restoration. The nuclear AcPms1 marker indicated that three of these 50 plants were homozygous dominant at $M s$, revealing that selfpollination of B2354A had occurred; all of these plants were male fertile. The AcPms 1 marker predicted that 30 of 50 flowering plants from B2354A were heterozygous at $M s$; however, only eight of these plants were visually scored as male fertile. Scoring of male fertility restoration in B2354A was especially difficult in the field environment due to low pollen production, with five plants scored as male fertile out of 17 predicted by the AcPms 1 marker to possess a dominant allele at $M s$. This observation is consistent with experience over years that fertility restoration is problematic for B2354A, and that the frequency of the dominant $M s$ allele in $\mathrm{B} 2354 \mathrm{~B}$ was estimated by the AcPms 1 marker to be 0.36 .

Acetocarmine staining of pollen from the three testcross families revealed significant differences for stainable pollen among progenies possessing dominant $M s$ allele(s). The two-way ANOVA for the percentage of stainable pollen revealed that the testcross family and the family-byenvironment interaction were highly significant $(P<0.001)$, and the environment was just below the significance level $(P=$ 0.0571). Across the three environments, the percentage of stainable pollen on male fertile testcross progenies from Ski was very high at $98.4 \%$ to $99.6 \%$ and slightly lower at $82.1 \%$ to $99.1 \%$ for AC (Figs. 3 and 4, Table 1). B2354B showed significantly lower stainable pollen at $13.1 \%$ to $68.3 \%$ (Figs. 3 and 4, Table 1). The correlation between the percentage of stainable pollen and germination was significant $(P<$ $0.001)$, although it was only 0.45 . Other researchers have reported low correlations between pollen germination and stainability using acetocarmine, cotton blue, or fluorescein diacetate (Ali et al., 1984; Ockendon and Gates, 1976a, 1976b). Overall, these previous studies reported pollen germination rates of $50 \%$ or less, and it is not clear if the low germination was due to the medium type, amounts of sucrose and/or microelements, or other factors (Gomes et al., 2000; Ockendon and Gates, 1976a). Therefore, staining of onion pollen must be considered as an indication of pollen quality, but not viability.

Over the years, we observed that male fertility restoration by the dominant $M s$ allele from Ski is clearly visible with copious pollen production (Fig. 2). In this research, Ski showed complete agreement between the AcPms 1 marker and male fertility restoration, as well as a significantly higher percentage of stainable pollen (Table 1, Figs. 3 and 4). For $\mathrm{AC}$, frequencies of male fertile plants in testcross families carrying the dominant $M s$ allele agreed with predictions of the AcPms 1 marker. However significantly lower pollen stainability was observed relative to Ski (Table 1), consistent with reduced penetrance of the dominant $M s$ allele from AC, as previously reported by Melgar and Havey (2010). Male sterility in inbred B2354A has been problematic across many seed production cycles. For plants of B2354A predicted by the marker to possess the dominant $M S$ allele, visible and stainable pollen markedly decreased in the field environment (Table 1), and fertility restoration was difficult to visually score. However, plants of B2354A predicted by the AcPmsl to be homozygous recessive at $M s$ were visually scored as male sterile, and this marker should be useful for purging the dominant $M s$ allele from B2354B.

In conclusion, we observed that dominant $M s$ alleles from different sources are associated with significantly different amounts of stainable pollen (Table 1), thus complicating visual selection against the male fertility restoration allele at $M s$. The $a c c D$ cytoplasmic marker together with the AcPms 1 nuclear marker correctly predicted male sterility across all three populations, although not necessarily male fertility restoration. Although Khar and Saini (2016) observed that these markers were not completely accurate in germplasm from the Indian subcontinent, we can recommend their use for marker-aided selection of maintainer lines for onion populations of European or North American origins (Havey and von Kohn, 2017) toward the development of male sterile inbred lines for the production of onion hybrids.

\section{Literature Cited}

Ali, M., R.D. Dowker, L. Currah, and P.M. Mumford. 1984. Floral biology and pollen viability of parental lines of onion hybrids. Ann. Appl. Biol. 104:167-174.

Currah, L. and D.J. Ockendon. 1978. Protandry and the sequence of flower opening in the onion. New Phytol. 81:419-428.
Goldman, I.L., G. Schroeck, and M.J. Havey. 2000 . History of public onion breeding programs and pedigree of public onion germplasm releases in the United States. Plant Breed. Rev. 20:67-103.

Gomes, P.R., M.C.B. Raseira, A. Garcia, and J.B. Silva. 2000. Germinação in vitro do pólen de cebola (Allium cepa L.). Agropec. Clima Temperado 3:193-198.

Havey, M.J. 1993. A putative donor of S cytoplasm and its distribution among open pollinated populations of onion. Theor. Appl. Genet. 86:128-134.

Havey, M.J. 1995. Identification of cytoplasms using the polymerase chain reaction to aid in the extraction of maintainer lines from open pollinated populations of onion. Theor. Appl. Genet. 90:263-268.

Havey, M.J. 2000. Diversity among male sterility inducing and male fertile cytoplasms of onion. Theor. Appl. Genet. 101:778-782.

Havey, M.J. and B. Bohanec. 2007. Onion inbred line 'B8667 A\&B' and synthetic populations 'Sapporo Ki 1 A\&B' and 'Onion Haploid 1'. HortScience 42:1731-1732.

Havey, M.J. and C. von Kohn. 2017. Efficacy of molecular markers jnurf13 and AcPms1 for prediction of genotypes at the nuclear $M s$ locus in North American open pollinated populations of onion. HortScience 52:1052-1053.

Heslop Harrison, J.S. 1992. Cytological techniques to assess pollen quality, p. 41-48. In: M. Cresti and A. Tiezzi (eds.). Sexual plant reproduction. Springer Verlag, Berlin.

Jones, H.A. and A. Clarke. 1943. Inheritance of male sterility in the onion and the production of hybrid seed. Proc. Amer. Soc. Hort. Sci. 43:189-194

Khar, A. and N. Saini. 2016. Limitations of PCR based molecular markers to identify male sterile and maintainer plants from Indian onion (Allium cepa L.) populations. Plant Breed. 135:519-524.

Kim, S., C.-W. Kim, M. Park, and D. Choi. 2015. Identification of candidate genes associated with fertility restoration of cytoplasmic male sterility in onion (Allium cepa L.) using a combination of bulked segregant analysis and RNA seq. Theor. Appl. Genet. 128:22892299.

King, J.J., J.M. Bradeen, O. Bark, J.A. McCallum, and M.J. Havey. 1998. A low density genetic map of onion reveals a role for tandem duplication in the evolution of an extremely large diploid genome. Theor. Appl. Genet. 96:52-62.

Melgar, S. and M.J. Havey. 2010. The dominant Ms allele in onion shows reduced penetrance. J. Amer. Soc. Hort. Sci. 135:49-52.

Ockendon, D.J. and P.J. Gates. 1976a. Reduced pollen viability in the onion (Allium cepa). New Phytol. 76:511-517.

Ockendon, D.J. and P.J. Gates. 1976b. Variation in pollen viability in the onion (Allium cepa). Euphytica 25:753-759.

von Kohn, C., A. Kiełkowska, and M.J. Havey. 2013. Sequencing and annotation of the chloroplast DNAs of normal $(\mathrm{N})$ male fertile and male sterile (S) cytoplasms of onion and single nucleotide polymorphisms distinguishing these cytoplasms. Genome 56:737-742. 